https://doi.org/10.37208/tgn27122

\section{Potential risk of American mink to water vole populations in east Glasgow}

\section{B.J. Wijas ${ }^{1}$, R.A. Stewart \& D.J. McCafferty}

Institute of Biodiversity, Animal Health \& Comparative Medicine, College of Medical, Veterinary and Life Sciences, University of Glasgow, Glasgow G12 8QQ

${ }^{1}$ E-mail: bwijas@gmail.com

Water voles (Arvicola amphibius) have undergone a rapid decline in the U.K. over the last few decades, due in part to the high predation pressure from introduced American mink (Neovison vison) (hereafter "mink") (Strachan, 2011). The water vole population within the Greater Easterhouse area of Glasgow was recently found to be of national importance, since this area contains some sites with the highest densities of water voles recorded within the U.K. (Stewart et al., 2017, 2019). Although these populations are fossorial in dry grassland, the extensive network of watercourses within the Greater Glasgow area (Fig. 1) and the proximity to the Seven Lochs Wetland Park may make these populations potentially at risk from mink invasion.

Mink are distributed throughout the Greater Glasgow area (64 identified records) with the highest frequency of reports on the River Kelvin and the Forth and Clyde Canal, based on 1997-2017 records (Glasgow Museum Biological Record Centre, 2018; National Biodiversity Network Atlas, 2018). Interestingly, there seems to be few records of mink within the east of Glasgow (Fig. 1). This could be due to either the unsuitability of habitat for mink establishment or a lack of recording effort within the area. Mink could potentially access the fossorial water vole populations through the Luggie Water. This watercourse is directly connected to the River Kelvin and the Forth and Clyde Canal and linked to the Seven Lochs Wetland Park through the Bothlin Burn, therefore potentially serving as a corridor for mink (Fig. 2). Indeed, there was a recent sighting of mink on Johnston Loch, Gartcosh, in September 2014 (R.A. Stewart, unpublished data), which suggests that they are already present within the area.

Mink generally settle in close proximity to water, as their feeding habits and protection from predators depend on these habitat features (Gerell, 1970; Yamaguchi et al., 2003; Macpherson \& Bright, 2010; Ahlers et al., 2016). When settled in their territories, these predators generally forage within $10-50 \mathrm{~m}$ of streams (Macpherson \& Bright, 2010), but they can also forage up to $500 \mathrm{~m}$ from a watercourse if suitable foraging opportunities exist (Gerell, 1970; Yamaguchi et al., 2003). Additionally, mink can disperse across great distances overland between catchments, with one study reporting a mean dispersal distance in north east Scotland of $37.1 \mathrm{~km}$ (Melero et al., 2017). This highlights their potential ability to colonise grassland where fossorial water vole populations may be found.

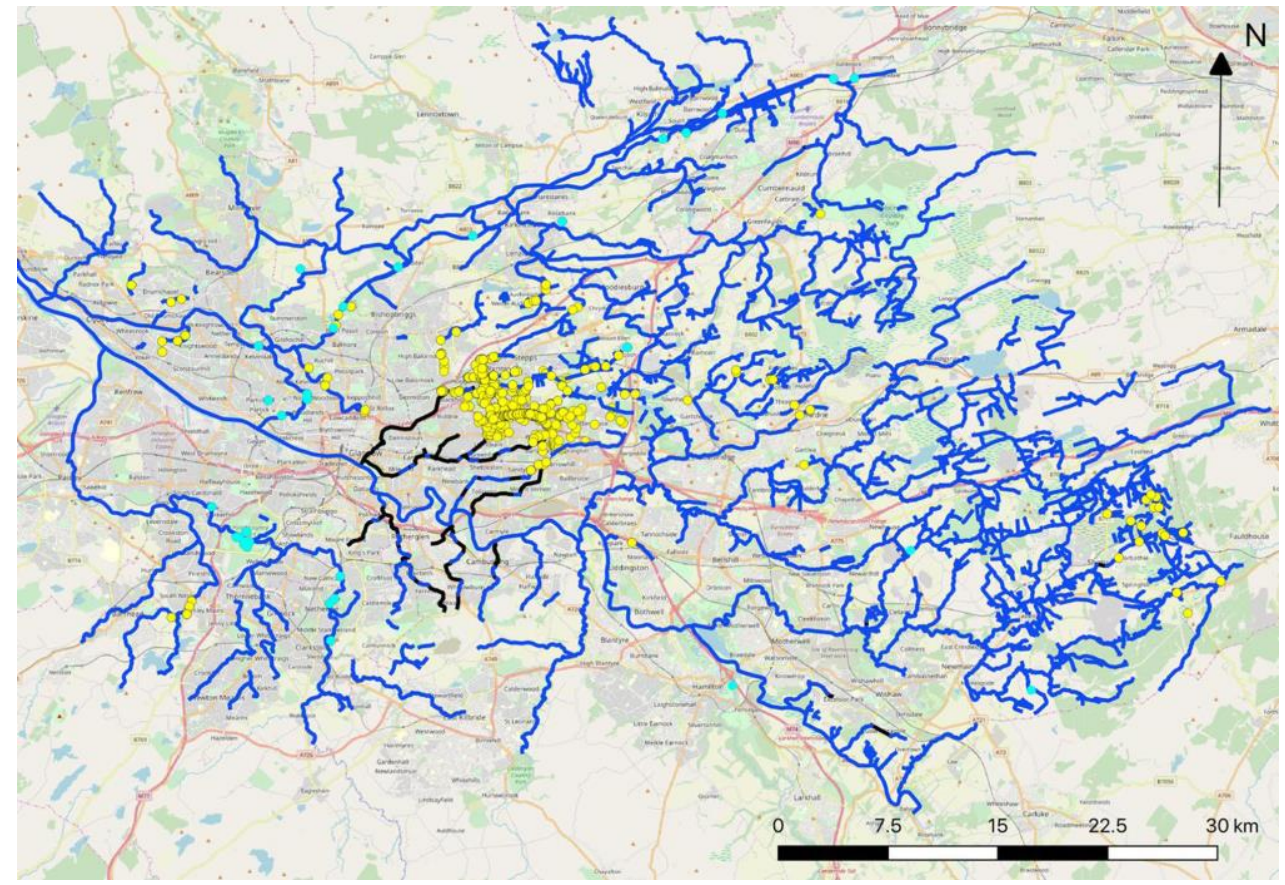

Fig. 1. Map of Greater Glasgow showing above-ground watercourses (blue) and underground watercourses (black). Water vole records 1994-2017 (yellow circles) and American mink records 1997-2017 (light blue circles) are plotted. 


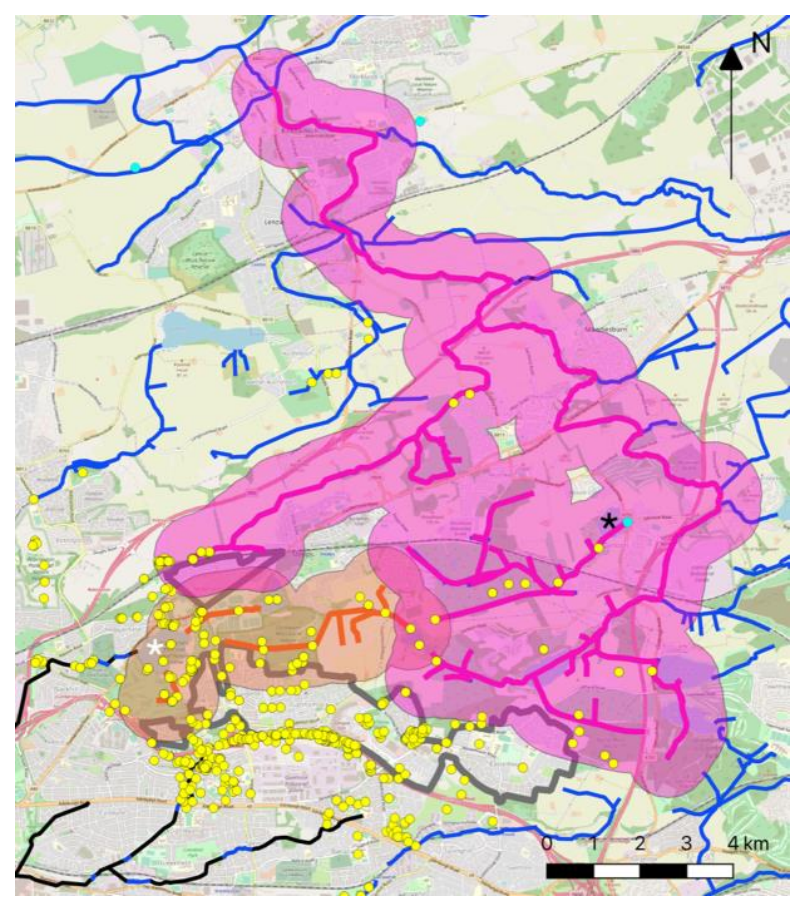

Fig. 2. Map of the east of Glasgow showing the records of American mink (light blue circles) and water voles (yellow circles). The $500 \mathrm{~m}$ zone surrounding the mink corridor (purple) represents the current potential distribution of mink. The $500 \mathrm{~m}$ zone (orange) represents the future potential distribution of mink around Hogganfield Loch and its tributaries (shown as orange lines). An urban land cover (buildings, parking lots, roads, maintained lawns and railroads) of over $80 \%$ is found within the thick grey margin in the bottom. Above-ground watercourses (blue) and underground watercourses (black). White asterisk: Hogganfield Loch; black asterisk: Johnston Loch.

In the light of the above, we attempted to identify the potential risk to fossorial water vole populations from current and future mink establishment in riparian habitats in the Greater Easterhouse area. This was undertaken by identifying fixed distance zones $50 \mathrm{~m}$ and $500 \mathrm{~m}$ around the putative mink corridor (Luggie Water and Bothlin Burn) using an open source geographic information system (QGIS Version 2.18) (Fig. 2) and plotting the number of water vole records (Glasgow Museum Biological Record Centre, 2018) within these zones obtained through a mix of opportunistic and systematic records of East Glasgow surveys (Table 1). This study assumed that the overlap between the potential mink distribution and the water voles could negatively affect water vole populations, as previously seen in linear riparian populations (Strachan, 2011). For the purposes of this study we use "record" to represent sites occupied by water voles. This analysis identified 27 water vole records that currently potentially face low risk from mink (between 50 and $500 \mathrm{~m}$ from a watercourse) and 11 records potentially facing high risk (between 0 and $50 \mathrm{~m}$ from a watercourse), representing respectively $4.3 \%$ and $1.8 \%$ of the total number of identified records (627) in the Greater Easterhouse area. Notably, if mink were to reach Hogganfield Loch (Table 1) and its associated tributaries, the number of records potentially at risk would increase considerably with low risk from mink increasing to $11.6 \%$ and high risk to $6.9 \%$ of records. Fortuitously, the built environment in Glasgow may reduce the risk of mink predation, as areas with more than $80 \%$ urban land cover have been found elsewhere to act as a barrier to mink dispersal (Ahlers $e t$ $a l ., 2016)$. However, given the history of establishment of mink within the U.K., mink have a high capability of dispersal and are likely to be more tolerant of human landscapes than was found in this recent study.

As water voles are protected under Schedule 5 (Section 9) of the Wildlife and Countryside Act 1981 (Strachan et al., 2011), it is important to conserve populations. Hogganfield Loch is currently a relocation site for water voles affected by urban developments and therefore it is crucial to determine whether or not mink are found within this area. We would recommend the implementation of a monitoring scheme using rafts to detect mink occupancy in this particular site (Reynolds et al., 2004), and would encourage local communities and naturalists throughout Glasgow to report sightings of mink for the benefit of this nationally important water vole population.

\begin{tabular}{lllll}
\hline & \multicolumn{2}{c}{ Current potential risk } & \multicolumn{2}{c}{ Future potential risk } \\
& Low & High & Low & High \\
\hline Number of records & 27 & 11 & 46 & 32 \\
Percentage of records & 4.3 & 1.8 & 7.3 & 5.1 \\
\hline
\end{tabular}

Table 1. Current number of water vole records (representing occupied sites in the Greater Easterhouse Area, Glasgow) that are potentially at risk and future records (in the same sense) that could potentially be at risk from American mink predation if mink reached Hogganfield Loch and its associated tributaries. High risk corresponds to records found within $50 \mathrm{~m}$ and low risk to records found within $500 \mathrm{~m}$ of a watercourse. The total number of water vole records and mink records was 627 and 64 respectively. 


\section{ACKNOWLEDGEMENTS}

We thank Richard Weddle from the Glasgow Natural History Society and Richard Sutcliffe from Glasgow Museums Biological Records Centre for providing us with records for mink and water voles. The work was funded by the Seven Lochs Wetland Park (Heritage Lottery Fund), Scottish Natural Heritage, Glasgow City Council and the People's Trust for Endangered Species. Thanks to Professor Xavier Lambin for very helpful review comments.

\section{REFERENCES}

Ahlers, A.A., Heske, E.J. \& Schooley, R.L. (2016). Prey distribution, potential landscape supplementation, and urbanization affect occupancy dynamics of American mink in streams. Landscape Ecology 31, 1601-1613. https://doi.org/10.1007/s10980-016-0350-5

Gerell, R. (1970). Home ranges and movements of the mink Mustela vison Shreber in southern Sweden. Oikos 21, 160. https://doi.org/10.2307/3543672

Glasgow Museum Biological Record Centre. (2018). NBN Atlas - Glasgow Museums BRC. https://registry.nbnatlas.org/public/show/dp160

Macpherson, J.L. \& Bright, P.W. (2010). Movements of radio-tracked American mink (Neovison vison) in extensive wetland in the UK, and the implications for threatened prey species such as the water vole (Arvicola amphibius). European Journal of Wildlife Research 56, 855-859. https://doi.org/10.1007/s10344-010-0383-z

Melero, Y., Oliver, M. \& Lambin, X. (2017). Relationship type affects the reliability of dispersal distance estimated using pedigree inferences in partially sampled populations: A case study involving invasive American mink in Scotland. Molecular Ecology 26, 4059-4071. https://doi.org/10.1111/mec.14154

National Biodiversity Network Atlas (2018). Arvicola amphibious (Linnaeus, 1758). NBN Atlas. https://species.nbnatlas.org/species/NHMSYS0020 546253\#records

Reynolds, J.C., Short, M.J. \& Leigh, R.J. (2004). Development of population control strategies for mink Mustela vison, using floating rafts as monitors and trap sites. Biological Conservation 120, 533543. https://doi.org/10.1016/j.biocon.2004.03.026

Stewart, R.A., Clark, T.J., Shelton, J., Stringfellow, M., Scott, C., White, S.A. \& McCafferty, D.J. (2017). Urban grasslands support threatened water voles. Journal of Urban Ecology 3(1) https://doi.org/10.1093/jue/jux007

Stewart, R.A., Jarrett, C., Scott, C., White, S.A. \& McCafferty, D.J. (2019). Water vole (Arvicola amphibius) abundance in grassland habitats of Glasgow. The Glasgow Naturalist 27(1), 10-19. https://doi.org/10.37208/tgn27102

Strachan, R., Moorhouse, T. \& Gelling, M. (2011). Water Vole Conservation Handbook. (3rd edition). Wild Conservation Research Unit, Abingdon.
Yamaguchi, N., Rushton, S. \& Macdonald, D.W. (2003). Habitat preferences of feral American mink in the upper Thames. Journal of Mammalogy 84, 1356-1373.

https://doi.org/10.1644/1545-1542(2003)084<1356: HPOFAM $>2.0 . \mathrm{CO} ; 2$ 